\title{
A Systematic Review of Blogging : Opportunities and Challenges
}

doi : https://doi.org/10.32628/CSEIT2172133

\section{Sahil Hans, Shaik Maqsad, Aditya Narayan Swami, Ashish Kumar}

School of Computer Science and Engineering, Lovely Professional University, Phagwara, Punjab, India

\begin{abstract}
Article Info

Volume 7, Issue 3

Page Number : 123-129

Publication Issue :

May-June-2021

\section{Article History}

Accepted : 05 May 2021

Published : 10 May 2021

By this research, we want to display the key factors of how effective blogging as technology is. We collected information curated by several researchers on the same for understanding their point of view as well. By doing this we found out what makes blogging the best way of sharing information online. We also analyzed the technological aspect of modern-day blogging which includes modern technologies being used, privacy rules and control as well as data analytics. By these approaches, we showed how blogging is not only the best medium for sharing information but can also help in other fields as well like marketing, education, data analysis, community development. With this research, we also wanted to highlight the downsides of using blogging or microblogging.
\end{abstract}

Keywords : Blogs, Micro-Blogging, Community Mining, Social Media, Mining.

\section{INTRODUCTION}

To know about blogging first we should know what is meant by Blog. In 1994, the beautiful world of blogging began, which is like more of a personal diary that people share online. A blog is a web journal or also referred to as an informational website which is employed to display information during a reverse chronological order that's with the newest posts appearing first at the top of the website. A blog is a shortened version of a weblog, it is a platform where a writer or a group of writers share their opinions and views on an individual subject. A collection of skills that one must supervise and run a blog is known as blogging. People saw an opportunity to communicate information in a new form of the way through online. The one that runs and controls a blog is named a blogger. He or she can share their opinion and knowledge on different topics. The number of bloggers on the web is increasing day by day and there are more than 570 million blogs on the web today.

The main purpose of starting a blog has many reasons, for example like personal use, business use, to rank your website that is increase visibility and to connect you to the relevant audience. Nowadays blogging is so popular and became the mainstream and a new source of information as new services began using them as tools for opinion-forming and outreach. Using blogging companies keep clients and customers up to date, visitors can comment and interact with you or your brand and you can offer your services and sell products. In the world of blogging, there are different kinds of blogs and bloggers, some of them are personal blog, business blog, professional blog, reverse blog,

Copyright: (C) the author(s), publisher and licensee Technoscience Academy. This is an open-access article distributed under the terms of the Creative Commons Attribution Non-Commercial License, which permits unrestricted non-commercial use, distribution, and reproduction in any medium, provided the original work is properly cited 
affiliate blog, media blog, freelance blog and niche blog which is also known for food, lifestyle, health, home decor, parenting, religious blogging. Freelance bloggers cover general topics and anything with a bit of research. A general blog is easy to monetize but it is hard to make visitors into customers. Thus general blogging is successful because bloggers in general blog build a portfolio that makes them attractive to businessmen and entrepreneurs who need quality content writing.

\section{Composing a post}

If you want your blog to ask readers in and keep them sending returns for updates. Great blogs are energetic and visually interesting, but they're also thoughtful and purposeful. Every post matters for generating and holding attention.[13] Consider the subsequent principles when composing:

- Make some extent: While the posts do not require any proper thesis it's important to own dissension, opinion, or purpose in mind once you write you're blog.

- Be concise: Use exact language and logical syntax to form your posts easy to read.

- Post often: Blogs should be updated regularly to carry every reader's interest. Actively generate fresh and very interesting content on a daily schedule.

- Consider inviting guest bloggers to appeal to various readers, widen your blog's scope, or refresh your view on the project.

- Proofread: Careless mistakes and errors can distract readers and cause you to appear less credible as a writer.

- Create visual interest: Appraise which aspects of your content would pair well with visual elements like photographs, figures, or videos. Hack large chunks of text with the visual elements to form your blog more understandable. Using Multimedia Audio and video interest helps to grab the reader's attention. Blogs give writers the chance to use designs, images, audio, and video to make much interesting writing. Cash in of those innovative ways to reinforce your presentation! Here are some guidelines to possess in mind once you choose your blog's multimedia elements

- Use appropriate content, size, and quality. Confirm your chosen images complement the layout of your text visually. Images should be easy to discover without blocking the text of a post. Choose the best quality image while also ensuring it's easy to load. We don't want our readers to blink at blurry pixels, but we won't want them to wait 10 seconds for something to load, either.

- When linking to a web video, think about using a screen shot from that video as your hyperlink. A screenshot of some interesting things can make a reader more likely to click on a link. It can provide a visible sneak, also demonstrate the clip's relevance to your post.

- Attribute your sources. Like ideas, images, audios, and videos are someone else's intellectual property. Whenever possible, provide captions for the reader. Even an easy caption -will help readers identify the object's origins. [12]

There are some tasks that a blogger performs on daily basis. These all things provide an experience to the bloggers, this helps to be a successful blogger:

- Writing blog posts every day

- Working on goals

- Checking emails and reply

- Promoting a blog on social media

- Connect on blogs

- Preparing a do-to list for next day

- Sharing other people's content

- Working weekly, monthly, and yearly tasks

- Editing and scheduling blog posts[12] 


\section{Importance of blogging}

We know blogs are a great way to generate fresh content on a website and provide a catalyst for email marketing, social media promotion to drive search traffic to your website. Here are two of the most important fields where blogging plays a very big role:

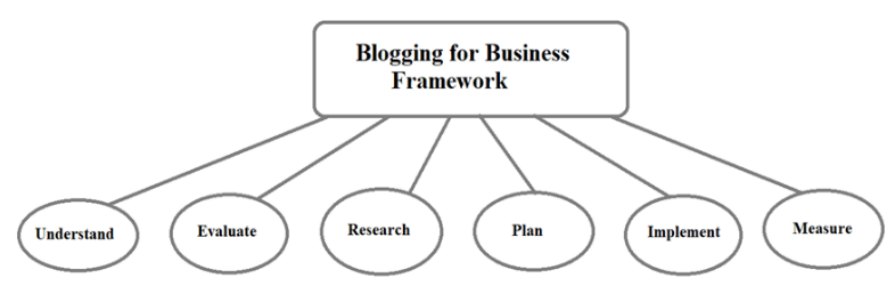

\section{LITERATURE REVIEW}

Guillaume Thevenot (7th June 2007): The author has published this paper in which it is written that blogging is one of the most popular social media tools. On social media, people share their opinions, insights, experiences, and perspectives through many different forms including texts, images, and videos. Blogging conversations between people begins with one person publishing an article in which readers give their comments. According to this article, around 120,000 new blogs are created every day worldwide, representing about 1.4 blogs every second, out of these blogs are travel-related. In this article author also discussed individual, collaborative, corporate blogs and traditional media blogs.[2]

Dou Shen, Jian-tao sun, Qiang Yang, Zheng Chen (2006): This article is on latent friend mining from blog data. There are a lot of blogs that are rich in providing data and that data provides rich resources for social community mining. Social community mining is the process of obtaining big data from usergenerated content on social media sites and mobile apps to extract patterns and act upon the information often for advertising to users or conducting researches. Latent friends are defined in this paper as people who share a similar topic distribution in their blogs. This article states the three approaches for latent friend detection cosine similarity-based method, Topic model-based method, and Two-level similarity based.[10]

Anne Bartlett-Bragg (2003): This article gives information about what is the blog and how could it be integrated into pedagogical (concern with teaching) practices to enhance learning. The paper introduces the blogging phenomenon and presents some options for educators. This paper state how will blogging enhance learning for everyone. This article explains the blogosphere in which blogs are considered collectively with their writers and readers as a distinct online network. This includes web designers, journalists, lawyers, software developers and knowledge management, and individuals with a desire to communicate their views on a topic or issue. The author also gives the five-stage blogging process: 1: establishment, 2: introspection, 3: reflective monologues, 4: Reflective dialogues, 5: Knowledge artifact.[5]

Child, J. T., Haridakis, P. M., \&Petronio, S. (2012) have published a paper describing the privacy rules and management for blogging. Authors have shown the study of different stages of blogging examining the functioning before and after blogging. Authors have classified different privacy rules and blogger's motives for the deletion of the previously posted information. They have curated data of activities of bloggers to show the deletion motives on pre-activity. They examined the contribution of blogging privacy rules, privacy management, and post-blogging deletion motives.[3]

Alsamadani, H. A. (2017) has published a paper describing how blogging helped students in increasing the effectiveness of writing skills. They have collected writing samples of students before and after blogging practices. They have shown how blog based writing 
can drastically improve writing skills in terms of language usage, style, and vocabulary choice. They have presented the result showing that how blogging revolutionized the writing skills, unlike the traditional methodology.[9]

Jones, M., and Alony (2008) have published a paper describing how blogging the new source of data analysis. They have shown how blogs can be used for analysis, also highlighting the advantages and disadvantages of the use of blogs and analyzed data. They showed how the blogosphere provides so much towards research and also showed the origin and evolution of blogs. They have shown how blogs can be a source of valuable and reliable data analysis.[1]

Lee, S., Hwang, T., \& Lee, H. (2006) have published a research paper showing corporate blogging strategies of fortune 500 companies. They have analyzed the blogging practices by using the framework. They have shown that most organizations maintain a high level of control over blogging strategies. They have also categorized the organization's emphasis based on bottom-up and top-down blogging strategies. This study also highlights the trends, issues, and future of corporate blogging.[7]

Zhang, J., Qu, Y., Cody, J., \& Wu, Y. (2010) have published a case study displaying the value and issues of micro-blogging in enterprises. They have curated data from several independent data sources like surveys, interviews, HR records. This case study showing how different phases vary for different users, they classified the phases as posting activities, reading behaviors, and perceived benefits. By this case study, they have found several aspects that can help practitioners and scholars to get an understanding of knowledge of workers using micro-blogging from the same enterprise.[6]
McCullagh, K. (2008) published a paper showing how blogging can raise privacy issues. They have collected and analyzed the data from several bloggers all around the world by surveys with the motives of finding the privacy practices of them while publishing the blogs. They have shown the results explaining why bloggers bring 'private' to public realm knowing the risk of privacy. They have categorized privacy in informational, accessibility, and expressive based on which they have examined the data.[4]

Zhang, C., Sun, J., Zhu, X., \& Fang, Y. (2010) have published a paper to show the challenges and opportunities of privacy and security of online social networks. Their goal was to show that even though the OSN is good for interactions and communications online but can cause privacy and security issues. They have examined and showed the design flows of the social networks, how there are conflicts between different design goals like usability, sociability, and security. They have analyzed social network theory by mitigating the design flaws and shown how core functionalities of OSNs can cause privacy and security issues.[11]

Kaplan, M. D., Piskin, B., \&Bol, B. (2009) have published a paper showing how educational blogging can help students in terms of marketing and soft skills. They have talked about how new approaches and practices can create a challenge for both instructors and students of marketing. They have shown how blogging can be an innovative and modern approach for students to develop better learning and improve their soft skills. They have curated data that displays the qualitative and quantitative outcomes of adding blogging to the curriculum of marketing management students.[8] 


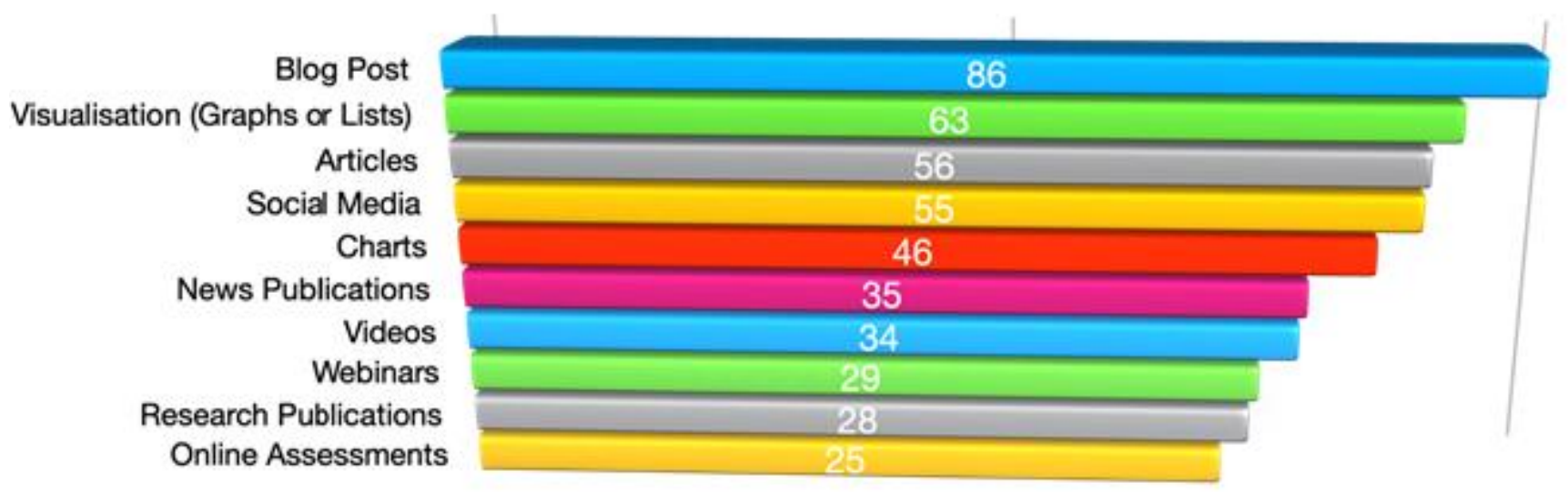

\begin{tabular}{|c|c|c|c|c|c|}
\hline Ref. & $\begin{array}{c}\text { Cost- } \\
\text { efficienc } \\
\mathbf{y}\end{array}$ & $\begin{array}{c}\text { Time } \\
\text { Effici } \\
\text { ency }\end{array}$ & Privacy & $\begin{array}{c}\text { Stab } \\
\text { ility }\end{array}$ & Intelligence \\
\hline McCullagh, K. (2008)[4] & $\checkmark$ & $\checkmark$ & $x$ & $x$ & $\checkmark$ \\
\hline $\begin{array}{c}\text { Kaplan, M. D., Piskin, B., } \\
\text { \&Bol, B. (2009)[8] }\end{array}$ & $\checkmark$ & $\checkmark$ & $x$ & $x$ & $\checkmark$ \\
\hline $\begin{array}{c}\text { Anne Bartlett-Bragg } \\
\text { (2003)[5] }\end{array}$ & $\checkmark$ & $\checkmark$ & $x$ & $x$ & $\checkmark$ \\
\hline $\begin{array}{c}\text { Jones, M. and Alony } \\
\text { (2008)[1] }\end{array}$ & $\checkmark$ & $\checkmark$ & $\checkmark$ & $x$ & $\checkmark$ \\
\hline $\begin{array}{c}\text { Alsamadani, H. A. } \\
\text { (2017)[9] }\end{array}$ & $x$ & $\checkmark$ & $x$ & $x$ & $\checkmark$ \\
\hline $\begin{array}{c}\text { Guillaume Thevenot } \\
(2007)[2]\end{array}$ & $\checkmark$ & $\checkmark$ & $\checkmark$ & $\checkmark$ & $\checkmark$ \\
\hline Zhang, C., Sun, J., Zhu, \\
(2010)[11]
\end{tabular}

( : observed, $\mathbf{X}$ : not observed)

\section{Methodology}

Blogs are easy to use and with a few clicks, you can share thoughts opinions news, and anything you want to share. Blogging refers to writing, photography, music, videos, and media that's self-published online. A blog is a type of website which provides information on any specific topics and sometimes many topics. The blog can be used for anything which involves communicating or building information on the World Wide Web. Teaching and education are the most common uses of a blog. Your blog can be a personal diary, collaboration tool, and any type of sailing on the web. There is something because of which blogging so popular these days:

- It is flexible and portable: We can do blogging anywhere anytime because we can also do blogging by using mobile. With the help of mobile, we can easily post anything and make more customers.

- Keep clients up to date: If we do blogging on daily basis the clients stay up to date and they can easily know about the things which are new for them.

- Helps build trust with customers: Blogging can help in making trust with customers because while you are selling anything there must be a 
description about the product of the particular thing you are selling. With the help of blogging, we can make our product known to the customer in a good way.

\section{Results}

While there are some conflicts regarding the security and privacy of the user's data with users posting too much personal information we cannot ignore the fact how much blogging, in general, can affect the writing and thinking of individuals, as we have shown with researches that are already there. It is good that blogging is getting more common and popular for sharing information online whether through articles or posting on micro-blogging websites like Twitter, Reddit. It became a platform where anyone can share their thoughts without any restrictions and that is also its issue. With the information that we have gathered while doing this research, we like to talk about both advantages and disadvantages of this.

The advantage of blogging is first of all it provides a platform for everyone to share their thoughts online. Other than that it can improve writing and thinking ability. At present with the help of data science blogging is being used to collect the data of how an individual thinks about certain things and then that data is being used on several social media platforms for community mining. With the addition of blogging to the teaching curriculum, it has shown the potential of improving the learning and understanding abilities of students. Despite the fact of having an online presence main disadvantage of blogging is user information, not only the information like emails or passwords but the information that they post on the platforms. As we have seen in the data analysis done by researchers that some of the authors share too much personal information on their posts without knowing the concerns of privacy with the data. Every individual should know the categorization of their information in terms of what should be private and public.
We cannot categorize security and privacy as either advantage or disadvantage of blogging reason being continuous improvements and new techniques are being developed to enhance security and privacy but still privacy of data cannot be assured online. Most of it also depends upon the user awareness that is using the technology. We can take 2-factor authentication as an example at present most of the websites and apps provide the facility of $2 \mathrm{FA}$ but still the percentage of people using 2FA is less even if people know the advantage of using it.

\section{CONCLUSION}

In conclusion, we can say that blogging is a very powerful technology for sharing information and what we believe is the issues like privacy and security of data is temporary with continuous developments in the security field and increasing awareness. Benefits and usage of this will eventually increase in the future with continuously growing popularity.

\section{REFERENCES}

[1]. M. Jones and I. Alony, "Blogs - The New Source of Data Analysis," Proc. 2008 InSITE Conf., 2008.

[2]. G. Thevenot, "Blogging as a Social Media," Tour. Hosp. Res., vol. 7, no. 4, pp. 287-289, 2007.

[3]. J. T. Child, P. M. Haridakis, and S. Petronio, "Blogging privacy rule orientations, privacy management, and content deletion practices: The variability of online privacy management activity at different stages of social media use," Comput. Human Behav., vol. 28, no. 5, pp. 18591872, 2012.

[4]. K. McCullagh, "Blogging: Self presentation and privacy," Inf. Commun. Technol. Law, vol. 17, no. 1, pp. 3-23, 2008. 
[5]. A. Bartlett-Bragg, "Blogging to Learn," Knowl. Tree, vol. 4, pp. 1-12, 2003.

[6]. J. Zhang, Y. Qu, J. Cody, and Y. Wu, "A case study of micro-blogging in the enterprise: Use, value, and related issues," Conf. Hum. Factors Comput. Syst. - Proc., vol. 1, pp. 123-132, 2010.

[7]. Jones, M. and Alony, I.: Blogs - the new source of data analysis 2008.

[8]. M. D. Kaplan, B. Piskin, and B. Bol, "Educational blogging: Integrating technology into marketing experience," J. Mark. Educ., vol. 32, no. 1, pp. 50-63, 2010.

[9]. H. A. Alsamadani, "The Effectiveness of Using Online Blogging for Students' Individual and Group Writing," Int. Educ. Stud., vol. 11, no. 1, p. 44, 2017.

[10].D. Shen, J. T. Sun, Q. Yang, and Z. Chen, "Latent friend mining from blog data," Proc. - IEEE Int. Conf. Data Mining, ICDM, pp. 552-561, 2006.

[11].C. Zhang, J. Sun, X. Zhu, and Y. Fang, "Privacy and security for online social networks: Challenges and opportunities," IEEE Netw., vol. 24, no. 4, pp. 13-18, 2010.

[12].Rettberg, Jil Walker. Blogging. 2nd ed. Cambridge, UK: Polity Books, 2014.

[13].Ask Any Question On Blogging, SEO, Web \& Social Media https://www.nairaland.com/3207887/askquestion-blogging-seo-web/5, 2016.

\section{Cite this article as :}

Sahil Hans, Shaik Maqsad, Aditya Narayan Swami, Ashish Kumar, "A Systematic Review of Blogging : Opportunities and Challenges", International Journal of Scientific Research in Computer Science, Engineering and Information Technology (IJSRCSEIT), ISSN : 2456-3307, Volume 7 Issue 3, pp. 123-129, May-June 2021. Available at doi : https://doi.org/10.32628/CSEIT2172133

Journal URL : https://ijsrcseit.com/CSEIT2172133 